\title{
Ariela Schnirmajer, Ciudades, retazos ardientes. La cuestión social en las Escenas norteamericanas de José Martí.
}

\author{
Buenos Aires, Corregidor, 2017, Nueva Crítica Hispanoamericana, 320 \\ páginas ${ }^{1}$
}

\section{María Fernanda Pampín}

Nos encontramos hoy entre tantos amigos para celebrar la publicación de Ciudades, retazos ardientes. La cuestión social en las Escenas norteamericanas de José Martí de Ariela Schnirmajer. Estoy acá con una personalidad desdoblada, como editora y como investigadora interesada en la obra martiana. Cuando Schnirmajer propuso su libro a la editorial ya conocía su trabajo desde hacía largo tiempo, pero no había leído la tesis completa. Este libro es el producto de su tesis que adaptó a un formato de libro académico, como solemos decir, más amable para el lector. La publicación de un libro siempre es un motivo de celebración. En este caso, la celebración es mayor cuando sabemos que el libro fue producto de un enorme esfuerzo y de largo tiempo de trabajo.

Creo necesario hacer algunas aclaraciones iniciales para comenzar esta lectura. La obra de Martí suscitó la atención académica de autores cubanos y latinoamericanos de manera constante desde hace algo más de un siglo. La producción de estudios sobre Martí no ha cesado y no sólo en el ámbito literario sino también en el de otras disciplinas como la historia, la sociología, la política y la filosofía, aunque también durante las últimas tres décadas, desde diferentes espacios y a través de nuevas textualidades, se han expresado en estos debates cineastas, fotógrafos y artistas plásticos cubanos.

En este contexto, pensé varias cuestiones. La primera radica en la dificultad de recortar un corpus en la obra de José Martí. La segunda se vincula con una complejidad para cualquier abordaje de su obra con el que nos encontramos los investigadores que nos dedicamos a ella a causa de la pluralidad de interpretaciones que admite y por la cantidad de bibliografía existente. Esto significa que no solo nos encontramos con una gran

Cita sugerida: Pampín, M. F. (2017). [Revisión del libro Ciudades, retazos ardientes. La cuestión social en las Escenas norteamericanas de José Martí por Ariela Schnirmajer]. Orbis Tertius, 22(25), e048. https://doi.org/10.24215/18517811e048 
cantidad de publicaciones sino que, además, esas publicaciones no cesan de aparecer. Esto implica desde el principio un enorme desafío y constituye, en definitiva, una problemática que inquieta y preocupa a cada uno de los investigadores que trabajan con autores muy transitados por la historia crítica. Martí no es la excepción en este caso y, entendido como un clásico, es quizás uno de los autores latinoamericanos más estudiados.

No obstante, no solo es preciso manejar con habilidad la bibliografía crítica martiana. Recortar un objeto de análisis en esa marea de publicaciones y entre todos los tomos de la obra de Martí es otra dificultad. Y pese a ello, en algún momento, sin embargo, es preciso hacer un recorte y comenzar a escribir.

Lo primero que se me ocurrió pensar fue en la existencia de escasos abordajes críticos sobre las Escenas norteamericanas pensadas como un corpus. Recordamos, por supuesto, importantes estudios que abordan las escenas de manera parcial. Se publicó en 2003 la edición de Archivos En los Estados Unidos, Periodismo de 1881 a 1892, coordinada por Roberto Fernández Retamar y Pedro Pablo Rodríguez, que recoge las crónicas conocidas hasta el momento y una serie de artículos críticos que abordan los textos. Al margen de esta colección, los ensayos de Julio Ramos, Susana Rotker, Javier Lasarte, Ángel Rama, Beatriz Colombi o Iván Schulman, por nombrar algunos de los más importantes, fueron de gran relevancia para los estudios martianos. En relación al resto de la obra, las Escenas no fueron aún lo suficientemente estudiadas. El libro de Ariela viene a salvar esta cuestión. Entre todos estos estudios, Ariela encontró una zona de debilidad dentro de la monumental bibliografía martiana (algo que ya podría considerarse una hazaña en sí misma) que le permitió hallar un tema propio y que merecía el esfuerzo de proponer una investigación e iniciar una discusión con otros colegas. Ariela construye un mapa crítico de los debates en los que se inscribe la investigación que sustenta su libro y va mucho más allá porque no solo se ocupa de la bibliografía crítica sobre la obra de Martí sino que además evidencia discusiones a partir de un aparato teórico muy actualizado y un acceso a fuentes fidedignas sobre el mundo laboral que revelan un intenso trabajo de archivo. Su hipótesis central sostiene que las crónicas martianas, a la vez que radicalizan sus concepciones políticosociales, significan una maduración de su estética y de las marcas de estilo. De este modo, el mundo del trabajo va adquiriendo mayor espacio en las entregas a medida que los conflictos entre empresarios y trabajadores se va agudizando.

De todo el volumen de crónicas, la autora pone el foco en las entregas publicadas por Martí en La Nación de Buenos Aires aunque se ocupa también de otras publicaciones como La Opinión Nacional de Caracas o El Partido Liberal de México. Divide su libro en dos partes bien diferenciadas. La primera de ellas atiende a momentos anteriores al exilio neoyorquino que considera altamente significativos, de un modo u otro, para la preparación del autor como cronista moderno. De la temprana formación de Martí en La Habana rescata el decisivo encuentro con su maestro, el poeta, traductor y editor de revistas literarias Rafael María de Mendive y aquellos que conformaban el círculo intelectual que lo rodeaba y la tradición ilustrada y liberal que lo sostenía. Son los años en que Martí fortaleció el fervor patriótico e independentista. Este período significó un punto fundamental en el desarrollo ideológico y estético martiano. Schnirmajer, se ocupa, de inmediato, del destierro español y de su pensamiento contradictorio respecto de España. Rescatamos de este período la impronta que los cuadros de Francisco de Goya dejará en la obra martiana y cuyas huellas la autora visibiliza en las Escenas norteamericanas. Schnirmajer propone que las observaciones que Martí hace en sus Cuadernos de apuntes sobre la representación pictórica de Goya implican una operación de écfrasis. Su lectura minuciosa y atenta revela que Martí utiliza luego este recurso para la construcción de los personajes de los estratos populares en la crónica periodística. Los modos en que analiza el intertexto visual sirven como ejemplificación de la operación de lectura de la autora: una mirada detallada y un cuidadoso análisis textual. 
El volumen continúa con el abordaje de las crónicas publicadas durante dos momentos muy especiales en la evolución del estilo del cronista. Schnirmajer asegura (y nos convence) de que el período mexicano es un momento de aprendizaje y que evidencia el embrión del estilo que desplegará en sus escritos de los años norteamericanos. Trata, por lo tanto, de encontrar los inicios del Martí periodista. Sostiene que es allí donde Martí descubre la heterogeneidad que caracteriza a nuestra América (una lectura propuesta antes por Beatriz Colombi, como la propia idea de embrión recién mencionada) y propone que en esta etapa Martí entra en contacto, por primera vez, con las luchas y los intereses de los trabajadores. Se centra, para ello, en la crónica que desarrolla la huelga de los sombrereros, donde Martí se enfrenta al derecho a la huelga y al conflicto entre patrones y obreros, un hecho que será fundamental para el desarrollo del pensamiento social del autor. Del período venezolano y sus entregas destinadas a La Opinión Nacional Ariela señala una fuerte diferencia entre las crónicas europeas y las norteamericanas para lo que hace hincapié en el estilo y el compromiso ético y político que distingue a estas últimas.

La segunda parte del libro, más extensa que la primera, atiende al corpus central del que se ocupa la autora. Si en un principio había estudiado el modo en que Martí llega a construir su figura de cronista, en los capítulos restantes, que conforman el núcleo que despliega los ejes centrales de su propuesta, se ocupa específicamente de la experiencia del autor en el periodismo norteamericano. Se aboca a la representación de los distintos sectores sociales de los Estados Unidos y reflexiona, al mismo tiempo, sobre la función, los límites y las posibilidades del periodismo, la emergencia de la cultura de masas y la industria cultural así como el rol del escritor en el proceso de transformación del mundo moderno, ese momento exacto en que la ciudad de Nueva York se transformaba en metrópoli y EEUU desnudaba sus intereses imperialistas y expansionistas. En ese complejo mundo moderno, Ariela se ocupa de la percepción que Martí tiene del contexto social y de la identificación, por momentos compleja, con los estratos sociales más bajos. En ese punto, reconoce los cambios en su pensamiento y las formas estéticas en las que Martí logra traducirlo.

Cuando Schnirmajer pensó en el formato del libro no se conformó con adaptar la tesis sino que siguió investigando no solo a partir de las sugerencias que recibió en el momento de la defensa sino en un diálogo continuo y fluido con sus compañeros de cátedra. Por eso, su tesis se amplió para este libro.

Ciudades, retazos ardientes se propone articular la producción periodística de Martí en una relación directa con otros discursos que circularon en el fin de siglo decimonónico. La red discursiva que sostiene la obra de Martí requiere un diálogo constante con otras producciones. Debido precisamente a esa multiplicidad discursiva, Ariela pone en circulación enfoques teóricos y críticos que, aunque parecen exceder en rigor el campo literario, en la medida que se apoyan también en el discurso historiográfico, sociológico, económico y político, aportan una perspectiva en la que las Escenas norteamericanas y el ejercicio del periodismo en Martí alcanzan su plenitud. Permite, además, reflexionar sobre otras cuestiones que participan de diferentes modos de esa problemática en la cultura latinoamericana.

Ariela entiende que en la crónica martiana, el trabajo de escritura se vuelve un ejercicio de lectura. Una cuestión que puede verse en su proximidad con la tradición norteamericana, en especial en la obra de Mark Twain. Es en esta parte que me interesa destacar, además, el análisis de las crónicas en relación con la prensa gráfica, un aspecto que resulta absolutamente innovador en las lecturas martianas. Por un lado, en la representación de los sectores marginales a través de las fotografías del periodista danés Jacob Riis, autor de How the Other Half Lives: Studies Among the Tenements of New York (1890), Ariela propone un diálogo entre el trabajo de Riis, pionero en el fotoperiodismo, y la crónica. Por el otro, en el semanario satírico Puck. Schnirmajer pone en relación a la animalización de los actores sociales, en especial vinculados a la representación de las figuras del mundo político, una cuestión que también puede verse en las Escenas a través de una fuerte crítica a la corrupción, los grandes intereses económicos y el monopolio. La puesta en 
relación de la escritura de Martí con las imágenes satíricas de Puck revela que la autora se mueve dentro del archivo con comodidad. Podríamos asegurar que ese es su espacio indiscutible. Da a conocer textos desconocidos o antes muy poco estudiados, despliega, sistematiza y analiza críticamente, no solo la bibliografía martiana que considera un aporte fundamental y un punto de referencia sobre algunas de las líneas principales de su trabajo, sino que demuestra un profundo conocimiento del contexto social: de la sociedad norteamericana y mexicana en el siglo XIX, del surgimiento de los sindicatos, de las huelgas y de los reclamos de los trabajadores.

Si hace un momento nos preguntábamos sobre el legado de José Martí y sobre los estudios que suscita esta cuestión, esto nos dirige hacia otras preguntas en estrecha vinculación con la anterior. ¿Por qué se sigue escribiendo sobre Martí tanto tiempo después? ¿Por qué deberíamos leer este ensayo de Ariela sobre la obra de Martí? La respuesta es relativamente fácil de responder. Martí sigue generando lecturas e interés porque, y aquí voy a citar a Ariela Schnirmajer, "se trata de una escritura volcada al futuro, que plantea problemáticas que recorrerán el siglo XX” (y aquí me permito añadir, y el siglo XXI también). La vigencia y la actualidad del pensamiento martiano se sostienen en su capacidad de producir interpretaciones sobre América Latina. A partir de allí es posible pensar la complejidad de los vínculos entre América Latina y los E.E.U.U., un vínculo muy antiguo que cada vez se complejiza más, para reflexionar al mismo tiempo sobre la plutocracia como forma de gobierno, para pensar el mundo del trabajo, las confrontaciones sociales, las grandes huelgas, los sectores populares, las dificultades de los inmigrantes y el rol del intelectual en la vida social.

Por último quiero agregar que los estudios sobre Martí, sin duda el autor más estudiado por Schnirmajer, conforman solo una parte de sus investigaciones sobre el modernismo. Julián del Casal, Rubén Darío o Amado Nervo fueron, por ejemplo, otros autores que abordó. No obstante, este trabajo que publica ahora sobre Martí (unido a tantos otros que no integraron este volumen y que son producto de más de dos décadas de docencia e investigación en la cátedra de Literatura Latinoamericana I de la Universidad de Buenos Aires), forma parte de un conjunto de textos que la reconocen y la colocan en nuestro país como un referente en el modernismo latinoamericano.

\section{Notas}

1 Se publica la presentación del libro llevada a cabo el día 5 de abril de 2017 en Buenos Aires, en la Librería Caburé. 